DR. ANNA KRATZ (Orcid ID : 0000-0002-3664-3898)

Article type : Original Article

Fibrofog in daily life: An examination of ambulatory subjective and objective cognitive function in fibromyalgia

Anna L. Kratz, PhDª, Daniel Whibleyª,b,c, PhD, Samsuk Kim ${ }^{d}$, MS, Martin Sliwinskie, PhD, Daniel Clauw $^{c}, \mathrm{MD}, \&$ David A. Williams ${ }^{\mathrm{c}}, \mathrm{PhD}$

aDepartment of Physical Medicine \& Rehabilitation, University of Michigan, Ann Arbor, MI ${ }^{b}$ Epidemiology Group, School of Medicine, Medical Sciences and Nutrition, University of Aberdeen, Aberdeen, UK

'Department of Anesthesiology, Chronic Pain \& Fatigue Research Center, University of Michigan, Ann Arbor, MI

dDepartment of Psychology, University of Detroit Mercy, Detroit, MI

eCenter for Healthy Aging, Pennsylvania State University, University Park, PA

Word Count: 3798

References: 50 


\begin{abstract}
Objective: Perceived cognitive dysfunction in fibromyalgia (FM), "fibrofog," is common. Prior laboratory-based studies have limited our understanding of cognitive function in FM in daily life. The aim of this study is to explore levels of subjective and objective cognitive functioning and the association between subjective and objective aspects of cognition in persons with and without FM in the lived environment.
\end{abstract}

Methods: Participants ( $n=50$ adults with FM; $n=50$ adults without FM matched on age, sex, and education) completed baseline measures of subjective and objective (NIH Toolbox) cognitive functioning. Then, they completed ecological momentary assessments of cognitive clarity and speed and tests of processing speed and working memory, via a smart phone app, 5X/day for 8 days. Results: On baseline objective measures, the FM group demonstrated poorer cognitive functioning across three NIH Toolbox tests. There were no strong correlations between subjective and objective cognitive functioning in both the FM and control group. In the lived environment, the FM group demonstrated poorer subjective cognition and objective working memory; groups did not differ on processing speed. Momentary ratings of subjective cognitive dysfunction were significantly related to changes in objective processing speed but not working memory, with no group differences.

Conclusion: Findings indicate worse lab-based and ambulatory subjective and objective cognitive function for those with FM compared to those without FM. Similar associations between measures of subjective and objective cognitive functioning for the groups suggest that people with FM are not overstating cognitive difficulties. Future research examining contributors to ambulatory fibrofog is warranted.

Key words: fibromyalgia, cognitive dysfunction, fibrofog, ambulatory assessment, working memory, processing speed

This article is protected by copyright. All rights reserved 


\section{Significance and Innovations}

- This study investigates within-day fluctuations in subjective and objective cognitive function in the lives of people with fibromyalgia (FM) compared to a non-FM group.

- At baseline, the FM group showed moderate performance deficits and reported moderately worse cognitive function than the non-FM group; the groups were similar with regard to the correlation between subjective and objective measures of cognitive function.

- On ambulatory assessment, the FM group had poorer subjective cognitive function and objective working memory, but not worse processing speed compared to the non-FM group.

- For both groups, momentary changes in processing speed, but not working memory, were associated with subjective reports of cognitive function.

This article is protected by copyright. All rights reserved 


\section{Introduction}

Approximately 5 million adults in the United States are diagnosed with fibromyalgia (FM), a musculoskeletal disorder where pain is usually accompanied by a constellation of physical and mental symptoms (1-4). Approximately $70 \%$ of individuals with FM endorse cognitive dsyfunction, known as "fibrofog" (3-5), which contributes to negative health perceptions and difficulty maintaining relationships, working, communicating, driving, organizing, and initiating activities of daily life (3-5). Despite growing evidence that FM is also associated with objective dysfunction across multiple cognitive domains $(6,7)$, the totality of the evidence for impaired cognitive functioning in FM is equivocal, with a number of studies showing no difference or limited/focal differences in cognitive impairment between people with and without FM (8-17).

One gap is in our knowledge of fibrofog and objective cognitive functioning where it matters most - in the everyday lives of people with FM. Research to date has relied on cross-sectional designs and standardized neuropsychological tests, in a clinical environment, at a single visit. The controlled, artificial nature of this testing environment is fundamentally different from the real-world environment in which people perform cognitively demanding tasks $(18,19)$; consequently, these studies lack ecological validity and their relationship to performance in the real world remains an open question $(19,20)$. The "snapshot" of cognitive function from cross-sectional neuropsychological studies is further limited because it fails to capture intra-individual variations in cognitive function (21, 22). Variability in cognitive function in FM is important because fluctuating cognitive performance may itself be an indicator of poor cognition $(23,24)$ and of vulnerability to future cognitive declines $(25,26)$. Examining the variability of cognition within a person may also provide new insights into the association between subjective (perceived) and objective (performance-based) cognitive dysfunction in FM.

A number of studies have demonstrated a discrepancy between subjective and objective cognitive functioning in $\operatorname{FM}(16,27,28)$, with depressed mood, alertness/hypersensitivity to fibrofog, and fatigue implicated as contributing factors to the disconnect. We lack insight about whether these findings of poor correlation between subjective and objective cognition at a between-person level are different between those with and without FM and whether this is also seen in daily life as difficulty accurately perceiving small moment-to-moment fluctuations in objective cognitive functioning in FM.

The goal of this study is to use ambulatory assessment methods to examine subjective and objective cognitive functioning in adults with FM and matched controls without FM in daily life. We

This article is protected by copyright. All rights reserved 
compared the groups in terms of levels of cognitive functioning (subjective, and objective processing speed and working memory) and association between subjective and objective cognitive functioning. We expected the FM group to show lower levels of subjective and objective cognitive functioning on both baseline and ambulatory measures. But, we expected no group differences in terms of the correspondence of subjective and objective cognitive functioning, for either baseline or ambulatory data.

\section{Materials \& Methods}

Participants

Volunteers were eligible if they were: 1) $\geq 18$ years of age; and 2) able to fluently converse and read ( $6^{\text {th }}$ grade level) in English. Volunteers were excluded if they endorsed: 1) comorbid neurological disorder, learning disorder, or cognitive impairment; 2) current alcohol or recreational drug dependence or prolonged ( $\geq 5$ years) history of substance dependence; 3 ) visual or hearing impairment that would preclude cognitive testing; 4) diagnosis of untreated obstructive sleep apnea; or 5) atypical sleep/wake pattern (e.g. night-shift workers). Participants with FM fulfilled the 2016 American College of Rheumatology survey criteria (29); participants in the control group did not meet the criteria for FM and were matched to already-enrolled participants with FM based on sex, age, and education.

\section{Study Procedures}

Prior to initiation of study activities, the Medical Institutional Review Board at the University of Michigan (UM) approved all study procedures. Participants were recruited from the UM, through existing patient registries, community groups, placement of fliers in health centers and community settings, and advertisement on a university-based recruitment website (www.UMHealthresearch.org). Volunteers were screened for eligibility over the phone and provided written informed consent prior to beginning study activities. Data were collected between January and August, 2018.

Participation in this study involved a 90-minute baseline visit followed by an 8-day home monitoring period (i.e. a 1-day "run-in" period, followed by 7 days of data collection). At the baseline visit, enrolled participants completed a battery of self-report measures and standardized cognitive testing and were given data collection devices. At the conclusion of the home monitoring period, participants returned the devices via a postage paid return box to the lab for data processing. Participants were compensated up to $\$ 175$ for full completion of the study.

This article is protected by copyright. All rights reserved 
Participants were issued a ZTE Axon 7 mini smartphone, with a 5.2" display (1080 x 1920 pixels) and programmed with a customized study-specific app to administer ecological momentary assessment (EMA) measures and ambulatory cognitive tests. Participants were instructed to initiate the first of the five daily EMA and cognitive testing sessions upon waking. For the following four sessions, the smartphone was programmed to play an audible alert to prompt the respondent to complete EMA and cognitive assessments; alerts were programmed on a quasi-random schedule based on each person's typical waking time with scheduled intervals between prompts ranging between 3-4.5 hours(18).

\section{Measures}

Baseline self-report measures

Participants completed surveys of demographics, medications, and validated symptom surveys. The Multidimensional Inventory of Subjective Cognitive Impairment (MISCI)(30) consists of 10 -items that assess cognitive functioning, rated on two scales ranging from $1=$ not at all/never to $5=$ very much/very often, summed and converted to a T-score metric (Mean=50, SD=10); higher scores indicate better functioning. Pain was assessed with the Patient Reported Outcome Measurement Information System (PROMIS) Pain Intensity 3a short form, which assesses worst and average pain in the past 7 days (1="no pain" to 5="very severe" scale) and current level of pain (1="no pain" to 5="very severe"). Scores were summed and converted to T-score metric (Mean=50, $S D=10)$; higher scores indicate more pain. Depressive symptoms were measured with the Patient Health Questionnaire-8 (PHQ-8)(31) that assesses the frequency of 8 depressive symptoms in the past 2 weeks. Scores range from 0-24; higher scores indicate greater depressive symptomatology. Fatigue was assessed with a 4-item short form from the PROMIS fatigue item bank (32); scores are on a $\mathrm{T}$-score metric with a Mean=50 and $\mathrm{SD}=10$. Higher scores are indicative of higher fatigue. Baseline cognitive tests

Four National Institutes of Health (NIH) Toolbox (33) cognitive tests were administered via the NIH Toolbox iPad App (34). The Flanker task is a measure of attention and inhibitory control that requires participants to focus on a given stimulus while inhibiting attention stimuli flanking the target. The List Sorting task is a test of working memory where participants recall and sequence stimuli presented both orally and visually. The Dimensional Change Card Sort is a test of cognitive flexibility and attention where pictures are presented varying by shape and color; the target dimension to be used for sorting (shape/color) is indicated by a cue word on the screen. The Pattern Comparison task 
is a measure of processing speed where participants are given 85 seconds to respond to as many stimuli as possible, discerning whether two simple pictures are identical or not. The NIH Toolbox provides a fully corrected T-score for each test (Mean=50, $S D=10$ ) corrected for age, education, gender, and race/ethnicity. Higher scores indicate better functioning.

Ambulatory Assessments

A study-specific smart phone app was programmed to administer EMA measures and cognitive tests in a single assessment/testing session.

\section{Ecological momentary assessment}

Subjective cognitive functioning was assessed with two items from the PROMIS Applied General Concerns (35) item bank, adapted for momentary assessment. The items "How slow is your thinking right now?", rated on a scale of $0-100$, where $0=$ my thinking is very fast to $100=$ my thinking is very slow, and "How foggy is your thinking right now?" rated on a scale of 0-100 where 0=my thinking is very clear to $100=$ my thinking is very foggy, were averaged to produce an aggregate score where higher scores indicate worse subjective cognitive functioning. Cronbach's alpha=0.95, indicating excellent internal consistency.

\section{Ambulatory objective cognitive tests}

Two brief, valid, and reliable cognitive tests (18), were administered via the study-specific smart phone app following administration of EMAs.

\section{Symbol Search Test}

The Symbol Search is a test of processing speed, where participants saw a row of four symbol pairs at the top of the screen and two symbol pairs at the bottom of the screen. Participants decided, as quickly as possible, which symbol pair at the bottom matches a symbol pair at the top and select the matching pair by touching their selection. Seventy-five percent of trials contained a lure stimulus, meaning that one of the two symbols on a not-matching pair matched one of the symbols at the top (but the pair did not match). Stimuli were presented until a response was provided. Accuracy and reaction time (milliseconds) were recorded. Sixteen trials were administered per testing session. Two variables were calculated for sessions where accuracy was $\geq 70 \%$ : average reaction time and standard deviation (variability) in reaction time per session.

Symbol Search session accuracy was used to assess participant effort in completing the test. Rote responding (i.e. indiscriminant selection of responses with little or no effort) would be consistent 
with accuracy rates of about 50\%. Intentional poor performance ("faking bad") would likewise be expected to correspond with low accuracy and could be expected to play a role in cases where accuracy was $<50 \%$. Accuracy of $<70 \%$ was used as a conservative cut-point to indicate poor effort; this is consistent with the procedures used in the study to validate these measures (18).

\section{Dot Memory Test}

The Dot Memory is a test of working memory. Each trial consists of 3 phases: encoding, distraction, and retrieval. During the encoding phase, the participant is asked to remember the location of three red dots appearing on a 5X5 square grid. After 3-seconds, the grid is removed and the distraction phase begins, during which the participant is required to touch the F's in an array of E's. After the distraction task, an empty $5 \times 5$ square grid is presented and the participant must place the red dots (by touching the empty squares) in the correct locations. Participants press "Done" when finished. Four test trials are administered each session. Euclidian distance, or the collective distance of the three dots from their correct locations (total error), was calculated. Three variables were calculated for Dot Memory: Average, maximum, and standard deviation of Euclidian distances across the four trials of each session.

\section{Data analysis}

Descriptive statistics for demographic and baseline measures were calculated. Independent samples t-tests were used to test group differences in baseline survey and cognitive test scores. Group differences in correlations between subjective and objective cognitive functioning were also tested (36). Graphs of subjective and objective cognitive functioning were plotted using mean scores at each within-day measurement time point collapsed across days and by group. Linear regression was used to determine whether group membership (FM/non-FM) predicted aggregate subjective or objective cognitive functioning scores across all days of study. Six objective functioning scores were investigated in separate analyses: three for processing speed (mean, median, and standard deviation of response times; Symbol Search test), and three for working memory (mean, maximum, and standard deviation of the error scores; Dot Memory test). The first day of at-home data collection was excluded as a "training day". To account for practice-related improvements in performance on ambulatory cognitive tests, models were adjusted for session number (a continuous variable that reflected the number of times the participant had completed the cognitive tasks). To investigate associations between momentary changes in subjective and objective cognitive functioning, personcentered objective cognitive functioning variables (reflecting momentary deviations from the 
participant's mean for the variable of interest) were included in separate multilevel models, with subjective cognitive functioning as the outcome, adjusted for session number (i.e., possible practice effects); in a final model, an interaction term between the objective cognitive functioning variable and group was used to test for group differences. Analyses were performed using Stata (Version 15, StataCorp, College Station, TX). For significance tests, a $p$ value of less than 0.05 was used as the threshold to determine statistical significance.

\section{Results}

One hundred participants (50 FM, 50 non-FM) enrolled and provided data. The sample was mostly female and white, with an average age of 45 years; the FM group had a significantly higher rate of unemployed $\left(\mathrm{X}^{2}(1, \mathrm{~N}=100)=5.88, p=0.02\right.$; Table 1$)$. Participants were generally compliant with the data collection protocol, providing data for an average of $90.9 \%$ of possible assessment sessions; the FM group had, on average, 91.2\% complete data and the Non-FM group 90.5\%.

\section{Group comparisons of baseline measures}

The FM group reported significantly worse scores on subjective cognition, and measures of depressed mood, pain, and fatigue, and demonstrated poorer objective cognitive function on $\mathrm{NIH}$ Toolbox tests; however, differences on cognitive tests were <1SD (Tables 1 and 2). The FM group reported higher levels of taking medications that could affect cognitive functioning; chi-square tests indicate significant group differences across all six medication categories listed (all $p<0.05$; Table 1). Correlations between baseline subjective and objective cognitive function

The groups did not differ in terms of the correlations between subjective (MISCI scores) and objective cognition on the NIH Toolbox tests ( $p>0.06$ for all test of group differences). For both groups, higher subjective cognitive functioning was correlated with better objective cognitive performance on all NIH Toolbox tests, except for the List Sorting task, which showed no significant correlation with the $\mathrm{MISCl}$ in either group.

Effort on ambulatory cognitive testing

Accuracy on the Symbol Search task suggested good effort for both groups. Accuracy was $>70 \%$ for $3688 / 3781$ (98.8\%) of all sessions. The groups did not differ in terms of accuracy rates. For the FM group, accuracy was $>70 \%$ for $1784 / 1813$ (98.4\%) of sessions (range $=43.75-100.00 \%$; Median=100.00, Mean=95.81, SD=6.83). For the non-FM Group, accuracy was $>70 \%$ for $1904 / 1918$ (99.2\%) of sessions (range=18.75-100.00\%; Median=100.00; Mean=95.79; SD=6.32). Sixteen individuals, 8 within each subgroup, were identified as having had at least one session with $<70 \%$

This article is protected by copyright. All rights reserved 
accuracy. Of these, four participants ( $n=3 \mathrm{FM}, \mathrm{n}=1$ non-FM), had multiple sessions with low accuracy (range $=5-12$ sessions) and were identified as possible cases of low effort. No reaction time variables were calculated for low-accuracy sessions.

Sensitivity analyses, excluding the four participants who demonstrated repeated low accuracy/effort, were conducted for all ambulatory cognition analyses. The results with/without these four people did not change the magnitude or significance of any results. Therefore, results for the full sample are reported.

Aggregate ambulatory cognitive functioning scores

The FM group had poorer mean aggregate subjective cognitive functioning, and poorer working memory (Dot Memory test mean error score, maximum error score, and standard deviations of the error scores), all $p<0.01$. Although the FM group had, on average, slower processing speed (Symbol Search), the difference compared to the non-FM group was not statistically significant (Table 3). Standard deviation variables for reaction time (Symbol Search) and working memory (Dot Memory) reflect intra-individual variability in objective performance on these two cognitive tests (Table 3). While the FM group exhibited higher within-person variability, in absolute terms, for both reaction time and working memory, this group difference was statistically significant for working memory only. Plots of mean subjective and select objective cognitive functioning scores at each daily time point, by group are depicted in Figures 1 and 2.

\section{Associations between within-person subjective and objective cognitive functioning}

Irrespective of group membership and practice effects, significant associations were observed between within-person momentary changes in response time (mean, median, and standard deviation of response times) and subjective cognitive functioning. In contrast, there were no significant associations between momentary changes in working memory (mean, maximum, SD of error for the session) and subjective cognitive functioning (Table 4). Analyses that tested the interaction between objective test performance and group membership in predicting subjective cognitive function showed no evidence of a group effect on the association between any objective cognition variable and subjective cognitive function (all $p>0.16$ ).

\section{Discussion}

This study provides initial evidence of the characteristics of subjective ("fibrofog") and objective cognitive dysfunction in the daily lives of those with FM. Prior to examining cognitive functioning in vivo, we conducted a series of tests of subjective and objective cognitive functioning in 
the laboratory, using a standardized battery of measures. The FM group reported worse cognitive function compared to the non-FM group, with subsample scores for FM approaching 1SD lower than scores for the non-FM group. Consistent with prior research demonstrating worse performance on standardized neurocognitive testing in FM, the FM group demonstrated worse attention (Flanker \& Dimensional Card Sort tests), working memory (List Sorting), and processing speed (Pattern Comparison) compared to the non-FM group; however, the between-group differences in test performance were modest (<1SD). Furthermore, with the exception of scores on the Flanker task, which were $<1 S D$ below the normative mean, the FM group was within $1 / 2$ SD of the normative sample mean of 50. In sum, analyses of baseline data show that on standard lab-based cognitive tests and surveys of cognitive function, the FM group showed moderate performance deficits and reported moderately worse cognitive dysfunction; The FM group reported far more subjective cognitive difficulties compared to those without FM, but findings that the FM group did not differ in terms of correlation between subjective and objective measures suggest that these complaints were not out of proportion to the cognitive deficits they demonstrated on baseline tests.

In terms of real-world ambulatory cognitive functioning, those with FM demonstrated poorer subjective cognitive dysfunction and objective working memory, but not significantly worse processing speed, compared to those without FM. The lack of processing speed impairment in the FM group is in contrast to previous studies showing slower cognitive processing in FM (37-40). Partially consistent with expectations, the FM group also showed greater intra-individual variability in working memory, but not in processing speed, compared with controls. Given that the lab-based test of processing speed showed significant group differences, the finding that the real-world test of this domain did not reveal group differences was unexpected. Reasons for lack of group differences on this ambulatory test may be due to a number of factors that warrant further exploration. It may be that the ambulatory reaction time task used in this study is not adequately sensitive to actual group differences in processing speed; processing speed is a relatively basic, "lower-order" cognitive domain that underlies and mediates higher-order cognitive functions, such as executive functioning and memory $(41,42)$. As such, deficits in processing speed in FM may be relatively modest compared with FM-related deficits in higher order cognitive domains. This is consistent with findings from a recent meta-analysis (6) showing that a specific aspect of executive functioning - inhibitory control - showed the largest effect size between people with FM and healthy controls, whereas processing speed showed a relatively smaller effect (6). Like the results from this meta-analyses, data from the current study suggest likely specificity in cognitive deficits in FM. Another possibility is

This article is protected by copyright. All rights reserved 
that the ambulatory Symbol Search testing sessions may not have been challenging or lengthy enough to be sensitive to FM-related deficits. For this and other unidentified reasons, it may be that group differences in processing speed only emerge in the controlled environment of the laboratory and not in real-world settings.

Findings for focal deficits (worse working memory but not worse processing speed) for the FM subgroup, combined with comparable Symbol Search accuracy rates for the two groups, do not suggest that people with FM are demonstrating poor test motivation, "faking bad", or global impairment. Previous studies have shown evidence of poor effort on tests among people with FM seeking disability benefits (43). But, even in studies that have found evidence of high rates of poor effort on cognitive testing in FM, effort did not totally explain dyscognition (44) and was not found at a higher rate in FM compared to other chronic pain conditions (16). Still, other studies have found no evidence for poor effort in $\mathrm{FM}(10,45,46)$ or for even greater achievement motivation in those with FM compared to age-matched controls (47).

Consistent with findings for baseline data, the association of subjective and objective cognitive functioning in daily life were not significantly different for those with compared to without FM. For both groups, only fluctuations in processing speed, but not working memory, were significantly related to concurrent ratings of subjective cognitive functioning such that times of worse than usual reaction time were associated with lower subjective cognitive clarity and speed. It is plausible that the lack of an association between working memory and subjective cognitive dysfunction is due to the fact that perceived memory ability was not assessed in the EMA items, which assessed cognitive clarity and speed. The finding that the groups were similar in terms of moment-to-moment correspondence between reaction time and subjective cognition does not support perceptual hypersensitivity to or perceptual exaggerations of fluctuations in objective cognitive performance in persons with FM.

\section{Study Limitations}

Although this study represents a crucial step in improving the ecological validity of cognitive assessment of fibrofog by assessing performance in the lived environment, the tests did not assess performance of real-world cognitive tasks. We assessed a relatively limited number of cognitive domains; it may be that larger group differences would emerge on tests of other domains (e.g., executive functioning) (6). The study did not include a standardized assessment of effort on baseline cognitive tests, so it is not clear whether motivation played a role in the findings; however, there were 
low rates of poor effort on ambulatory tests of cognition and removal of individuals who demonstrated occasional poor effort did not alter results. Although data on employment status was collected, we did not assess disability status, and therefore cannot comment on its impact on performance. In this first ambulatory study of cognitive function in FM, we aimed to examine how people with FM differ from individuals without FM and without significant symptoms (e.g., pain, fatigue); future studies that compare people with FM to people without FM but with chronic pain and fatigue would provide additional, crucial insights into the characteristics and mechanisms of fibrofog. Such comparisons are critical to understanding which aspects of fibrofog are related to having chronic pain (generally) and which are unique to FM. Fibromyalgia symptoms are observed on a spectrum, often referred to as fibromyalgianess (48-50); as such, FM/non-FM dichotomies such as the one considered here essentially mask both within-group diversity in overall fibromyalgianess and the overlap between groups in terms of distribution of specific symptoms (e.g., fatigue). The association between cognitive functioning and both fibromyalgianess and specific symptom burden profiles warrants examination in larger and more diverse samples. Our aim was to examine and compare subjective and objective cognitive functioning in adults with and without FM. Accordingly, we did not adjust for distinguishing symptoms of FM in our statistical models (e.g. pain, fatigue, depression). However, future analyses of this data will explore the interplay and impact of hallmark FM symptoms on daily cognitive function. 


\section{Acknowledgements}

Research reported in this publication was supported by the National Institute of Arthritis and Musculoskeletal and Skin Diseases of the National Institutes of Health (award number K01AR064275; PI: Kratz). The Michigan Institute for Clinical \& Health Research (MICHR: NIH award number UL1TR002240) provided subject recruitment support through the UMHealthResearch.org website. The content is solely the responsibility of the authors and does not necessarily represent the official views of the National Institutes of Health.

\section{Conflict of Interest.}

The authors have no conflicts of interest to report.

This article is protected by copyright. All rights reserved 


\section{References}

1. Wolfe F, Ross K, Anderson J, Russell IJ, Hebert L. The prevalence and characteristics of fibromyalgia in the general population. Arthritis Rheum. 1995;38(1):19-28.

2. Lawrence RC, Felson DT, Helmick CG. Estimates of the prevalence of arthritis and other rheumatic conditions in the United States. Arthritis \& Rheumatism. 2008;58(1):26-35.

3. Bennett RM, Jones J, Turk DC, Russell IJ, Matallana L. An internet survey of 2,596 people with fibromyalgia. BMC Musculoskelet Disord. 2007;8:27.

4. Arnold LM, Crofford LJ, Mease PJ, Burgess SM, Palmer SC, Abetz L, et al. Patient perspectives on the impact of fibromyalgia. Patient Educ Couns. 2008;73(1):114-20.

5. Katz RS, Heard AR, Mills M, Leavitt F. The prevalence and clinical impact of reported cognitive difficulties (fibrofog) in patients with rheumatic disease with and without fibromyalgia. J Clin Rheumatol. 2004;10(2):53-8.

6. Bell T, Trost Z, Buelow MT, Clay O, Younger J, Moore D, et al. Meta-analysis of cognitive performance in fibromyalgia. J Clin Exp Neuropsychol. 2018;40(7):698-714.

7. Wu YL, Huang CJ, Fang SC, Ko LH, Tsai PS. Cognitive Impairment in Fibromyalgia: A MetaAnalysis of Case-Control Studies. Psychosom Med. 2018;80(5):432-8.

8. Walteros C, Sanchez-Navarro JP, Munoz MA, Martinez-Selva JM, Chialvo D, Montoya P. Altered associative learning and emotional decision making in fibromyalgia. J Psychosom Res. 2011;70(3):294-301.

9. Walitt B, Fitzcharles MA, Hassett AL, Katz RS, Hauser W, Wolfe F. The longitudinal outcome of fibromyalgia: a study of 1555 patients. J Rheumatol. 2011;38(10):2238-46.

10. Park DC, Glass JM, Minear M, Crofford LJ. Cognitive function in fibromyalgia patients. Arthritis Rheum. 2001;44(9):2125-33.

11. Grace GM, Nielson WR, Hopkins M, Berg MA. Concentration and memory deficits in patients with fibromyalgia syndrome. J Clin Exp Neuropsychol. 1999;21(4):477-87.

12. Lee DM, Pendleton N, Tajar A, O'Neill TW, O'Connor DB, Bartfai G, et al. Chronic widespread pain is associated with slower cognitive processing speed in middle-aged and older European men. Pain. 2010;151(1):30-6.

13. Landro NI, Stiles TC, Sletvold $\mathrm{H}$. Memory functioning in patients with primary fibromyalgia and major depression and healthy controls. J Psychosom Res. 1997;42(3):297-306.

This article is protected by copyright. All rights reserved 
14. Kim SH, Kim SK, Nam EJ, Han SW, Lee SJ. Spatial versus verbal memory impairments in patients with fibromyalgia. Rheumatol Int. 2012;32(5):1135-42.

15. Walitt B, Roebuck-Spencer T, Bleiberg J, Foster G, Weinstein A. Automated neuropsychiatric measurements of information processing in fibromyalgia. Rheumatol Int. 2008;28(6):561-6.

16. Suhr JA. Neuropsychological impairment in fibromyalgia - Relation to depression, fatigue, and pain. Journal of Psychosomatic Research. 2003;55(4):321-9.

17. Miro E, Lupianez J, Hita E, Martinez MP, Sanchez Al, Buela-Casal G. Attentional deficits in fibromyalgia and its relationships with pain, emotional distress and sleep dysfunction complaints. Psychol Health. 2011;26(6):765-80.

18. Sliwinski MJ, Mogle JA, Hyun J, Munoz E, Smyth JM, Lipton RB. Reliability and Validity of Ambulatory Cognitive Assessments. Assessment. 2018;25(1):14-30.

19. Spooner DM, Pachana NA. Ecological validity in neuropsychological assessment: a case for greater consideration in research with neurologically intact populations. Arch Clin Neuropsychol. 2006;21(4):327-37.

20. Sbordone RJ. Ecological validity: Some critical issues for the neuropsychologist. In: Sbordone RJLCJ, editor. Ecological validity of neuropsychological testgin. Boca Raton, Fl: St. Lucie Press; 1996. p. 15-41.

21. Allard M, Husky M, Catheline G, Pelletier A, Dilharreguy B, Amieva H, et al. Mobile technologies in the early detection of cognitive decline. PloS one. 2014;9(12):e112197.

22. Timmers $\mathrm{C}$, Maeghs A, Vestjens $\mathrm{M}$, Bonnemayer $\mathrm{C}$, Hamers $\mathrm{H}$, Blokland A. Ambulant cognitive assessment using a smartphone. Appl Neuropsychol Adult. 2014;21(2):136-42.

23. Ram N, Rabbitt P, Stollery B, Nesselroade JR. Cognitive performance inconsistency: intraindividual change and variability. Psychol Aging. 2005;20(4):623-33.

24. West R, Murphy KJ, Armilio ML, Craik FI, Stuss DT. Lapses of intention and performance variability reveal age-related increases in fluctuations of executive control. Brain Cogn. 2002;49(3):402-19.

25. Bielak AA, Hultsch DF, Strauss E, MacDonald SW, Hunter MA. Intraindividual variability is related to cognitive change in older adults: evidence for within-person coupling. Psychol Aging. 2010;25(3):575-86.

26. Bielak AA, Hultsch DF, Strauss E, Macdonald SW, Hunter MA. Intraindividual variability in reaction time predicts cognitive outcomes 5 years later. Neuropsychology. 2010;24(6):731-41.

This article is protected by copyright. All rights reserved 
27. Castel A CR, Salvat M, Sala J, Padrol A, Perez M. Cognitive performance and memory complaints in chronic patients: with fibromyalgia versus without fibromyalgia. Rev la Soc Esp del Dolor. 2008;15:358-70.

28. Walitt B, Ceko M, Khatiwada M, Gracely JL, Rayhan R, VanMeter JW, et al. Characterizing "fibrofog": Subjective appraisal, objective performance, and task-related brain activity during a working memory task. Neuroimage Clin. 2016;11:173-80.

29. Wolfe F, Clauw DJ, Fitzcharles MA, Goldenberg DL, Hauser W, Katz RL, et al. 2016 Revisions to the 2010/2011 fibromyalgia diagnostic criteria. Semin Arthritis Rheum. 2016;46(3):31929.

30. Kratz AL, Schilling SG, Goesling J, Williams DA. Development and initial validation of a brief self-report measure of cognitive dysfunction in fibromyalgia. J Pain. 2015;16(6):527-36.

31. Kroenke K, Strine TW, Spitzer RL, Williams JB, Berry JT, Mokdad AH. The PHQ-8 as a measure of current depression in the general population. J Affect Disord. 2009;114(1-3):163-73.

32. Kratz AL, Schilling S, Goesling J, Williams DA. The PROMIS FatigueFM Profile: a self-report measure of fatigue for use in fibromyalgia. Qual Life Res. 2016;25(7):1803-13.

33. Gershon RC, Cella D, Fox NA, Havlik RJ, Hendrie HC, Wagster MV. Assessment of neurological and behavioural function: the NIH Toolbox. Lancet Neurol. 2010;9(2):138-9.

34. Brearly TW, Rowland JA, Martindale SL, Shura RD, Curry D, Taber KH. Comparability of iPad and Web-Based NIH Toolbox Cognitive Battery Administration in Veterans. Arch Clin Neuropsychol. 2018.

35. Cella D, Yount S, Rothrock N, Gershon R, Cook K, Reeve B, et al. The Patient-Reported Outcomes Measurement Information System (PROMIS): progress of an NIH Roadmap cooperative group during its first two years. Med Care. 2007;45(5 Suppl 1):S3-S11.

36. Diedenhofen B, Musch J. cocor: a comprehensive solution for the statistical comparison of correlations. PloS one. 2015;10(3):e0121945.

37. Montoro Cl, Duschek S, Munoz Ladron de Guevara C, Fernandez-Serrano MJ, Reyes del Paso GA. Aberrant cerebral blood flow responses during cognition: Implications for the understanding of cognitive deficits in fibromyalgia. Neuropsychology. 2015;29(2):173-82.

38. Cherry BJ, Zettel-Watson L, Shimizu R, Roberson I, Rutledge DN, Jones CJ. Cognitive performance in women aged 50 years and older with and without fibromyalgia. J Gerontol B Psychol Sci Soc Sci. 2014;69(2):199-208.

This article is protected by copyright. All rights reserved 
39. Reyes del Paso GA, Garrido S, Pulgar A, Duschek S. Autonomic cardiovascular control and responses to experimental pain stimulation in fibromyalgia syndrome. J Psychosom Res. 2011;70(2):125-34.

40. Veldhuijzen DS, Sondaal SF, Oosterman JM. Intact cognitive inhibition in patients with fibromyalgia but evidence of declined processing speed. J Pain. 2012;13(5):507-15.

41. Salthouse TA. The processing-speed theory of adult age differences in cognition. Psychol Rev. 1996;103(3):403-28.

42. Salthouse TA. General and specific speed mediation of adult age differences in memory. J Gerontol B Psychol Sci Soc Sci. 1996;51(1):P30-42.

43. Gervais RO, Russell AS, Green P, Allen LM, 3rd, Ferrari R, Pieschl SD. Effort testing in patients with fibromyalgia and disability incentives. J Rheumatol. 2001;28(8):1892-9.

44. Bar-On Kalfon T, Gal G, Shorer R, Ablin JN. Cognitive functioning in fibromyalgia: The central role of effort. J Psychosom Res. 2016;87:30-6.

45. Verdejo-Garcia A, Lopez-Torrecillas F, Calandre EP, Delgado-Rodriguez A, Bechara A. Executive function and decision-making in women with fibromyalgia. Arch Clin Neuropsychol. 2009;24(1):113-22.

46. Iverson GL, Le Page J, Koehler BE, Shojania K, Badii M. Test of Memory Malingering (TOMM) scores are not affected by chronic pain or depression in patients with fibromyalgia. Clin Neuropsychol. 2007;21(3):532-46.

47. Glass JM, Park DC, Minear M, Crofford LJ. Memory beliefs and function in fibromyalgia patients. J Psychosom Res. 2005;58(3):263-9.

48. Wolfe F. New American College of Rheumatology criteria for fibromyalgia: a twenty-year journey. Arthritis Care Res (Hoboken). 2010;62(5):583-4.

49. Wolfe F, Hassett AL, Walitt B, Michaud K. Mortality in fibromyalgia: a study of 8,186 patients over thirty-five years. Arthritis Care Res (Hoboken). 2011;63(1):94-101.

50. Wolfe F, Clauw DJ, Fitzcharles MA, Goldenberg DL, Hauser W, Katz RS, et al. Fibromyalgia criteria and severity scales for clinical and epidemiological studies: a modification of the ACR Preliminary Diagnostic Criteria for Fibromyalgia. J Rheumatol. 2011;38(6):1113-22.

This article is protected by copyright. All rights reserved 


\section{Figure Legend}

Figure 1. Plots of means for self-reported cognitive dysfunction by group at each within-day time point.

Figure 2. Plots of means for objectively measured cognitive function by group at each within-day time point.

This article is protected by copyright. All rights reserved 
Figure 1.

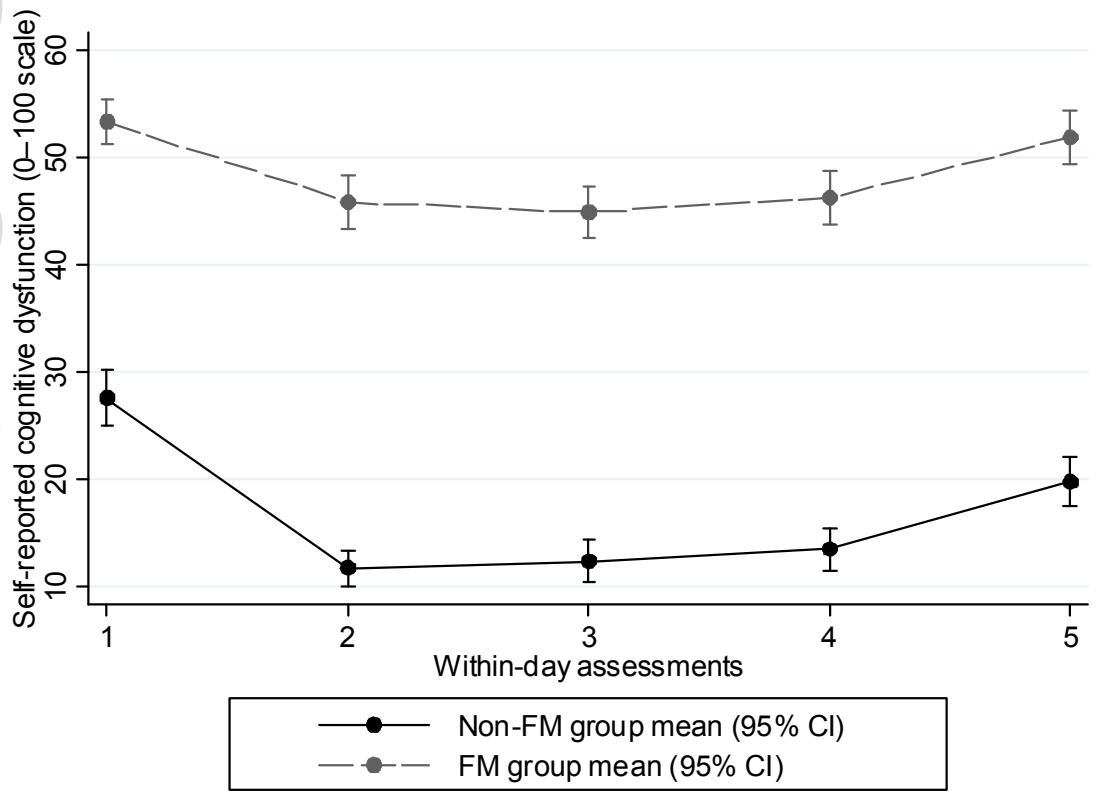

This article is protected by copyright. All rights reserved 
Figure 2.

a. Symbol search mean processing speed

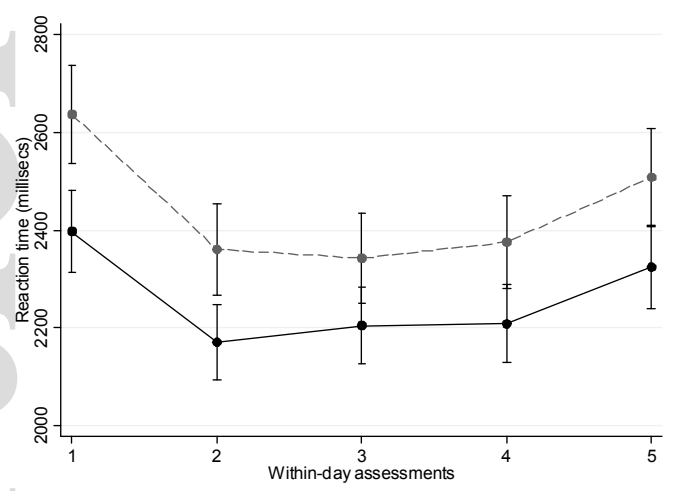

c. Dot memory task mean error

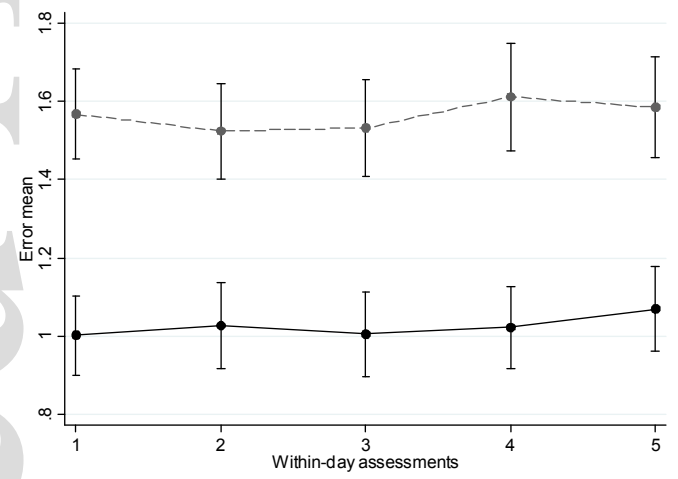

b. Symbol search SD of processing speed

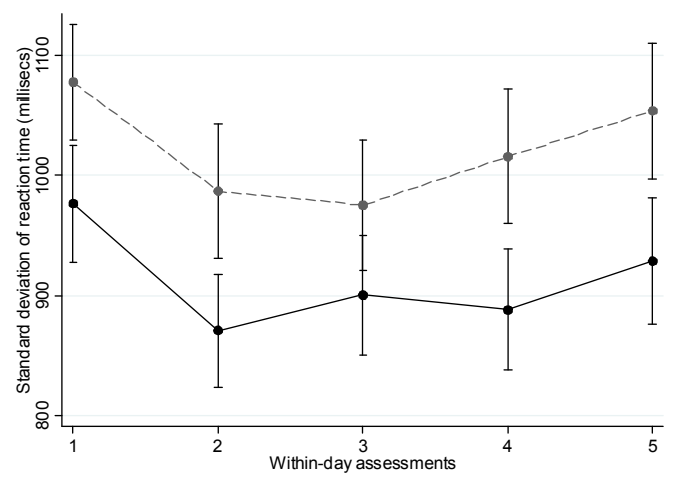

d. Dot memory task SD of the error

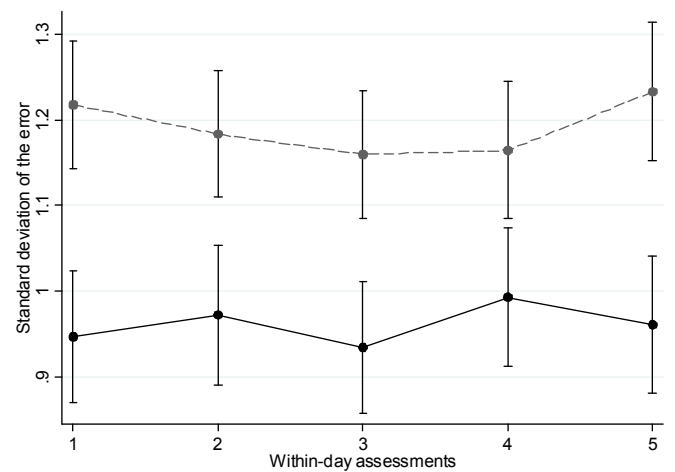

SD: standard deviation

$$
\begin{aligned}
& \longrightarrow-\text { Non-FM group mean } \\
& -95 \% \mathrm{Cl} \text { of the mean }
\end{aligned}
$$


Table 1. Participant descriptive statistics by group

\begin{tabular}{|c|c|c|c|}
\hline & $\begin{array}{c}\text { Total } \\
\mathrm{N}=100\end{array}$ & $\begin{array}{c}\mathrm{FM} \\
\mathrm{N}=50\end{array}$ & $\begin{array}{c}\text { Non FM } \\
\mathrm{N}=50\end{array}$ \\
\hline \multicolumn{4}{|l|}{ Age, years } \\
\hline Mean (SD) & $45.1(13.9)$ & $44.9(13.9)$ & $45.2(14.0)$ \\
\hline Range & $18-73$ & $20-70$ & $18-73$ \\
\hline Female, N (\%) & $88(88 \%)$ & $44(88 \%)$ & $44(88 \%)$ \\
\hline \multicolumn{3}{|l|}{ Education } & $15.8(2.0)$ \\
\hline \multicolumn{4}{|l|}{ Employment Status* } \\
\hline Full-time & & $19(38)$ & $21(42)$ \\
\hline Part-time & & $10(20)$ & $17(34)$ \\
\hline Student & & $4(8)$ & $5(10)$ \\
\hline Unemployed & & $20(40)$ & $11(22)$ \\
\hline \multicolumn{4}{|l|}{ Race } \\
\hline White & $81(81 \%)$ & $43(86 \%)$ & $38(76 \%)$ \\
\hline Black & $13(13 \%)$ & $5(10 \%)$ & $8(16 \%)$ \\
\hline Bi/multi-racial & $3(3 \%)$ & $2(4 \%)$ & $1(2 \%)$ \\
\hline Asian & $3(3 \%)$ & $0(0 \%)$ & $3(6 \%)$ \\
\hline \multicolumn{4}{|l|}{ Medication Categories, N (\%) } \\
\hline Opioid & & $16(32 \%)$ & $1(2 \%)$ \\
\hline SSRI & & $21(42 \%)$ & $9(18 \%)$ \\
\hline Tricyclic antidepressant & & $5(10 \%)$ & $0(0 \%)$ \\
\hline Pregabalin/gabapentin & & $8(16 \%)$ & $2(4 \%)$ \\
\hline Benzodiazepine & & $9(18 \%)$ & $2(4 \%)$ \\
\hline Sleep Aid & & $13(26 \%)$ & $0(0 \%)$ \\
\hline \multicolumn{4}{|l|}{ Symptoms (mean, SD) } \\
\hline $\begin{array}{l}\text { PROMIS pain intensity T- } \\
\text { score }\end{array}$ & $45.0(11.4)$ & $54.3(6.1)$ & $35.6(6.8)$ \\
\hline $\begin{array}{l}\text { PROMIS fatigue experience } \\
\text { T-score }\end{array}$ & $55.0(13.8)$ & $65.9(7.0)$ & $44.1(9.5)$ \\
\hline
\end{tabular}

This article is protected by copyright. All rights reserved 
Patient Health

$6.2(5.9)$

$10.6(5.2)$

$1.8(2.1)$

Questionnaire-8 (total score)

Note. Percentages may total to $>100$ because participants could select more than one category. SSRI= Selective serotonin reuptake inhibitors

This article is protected by copyright. All rights reserved 
Table 2. Baseline cognitive tests group comparisons

\begin{tabular}{|l|c|c|c|r|}
\hline Measure of cognitive function & \multicolumn{1}{|c|}{$\begin{array}{c}\text { FM } \\
\text { N=50 }\end{array}$} & $\begin{array}{c}\text { Non FM } \\
\text { N=50 }\end{array}$ & t & p \\
\hline $\begin{array}{l}\text { Multidimensional Inventory of } \\
\text { Subjective Cognitive Impairment } \\
\text { (MISCI) } \\
(\text { mean, SD) }\end{array}$ & $45.54(2.64)$ & $54.04(5.57)$ & -11.80 & $<0.001$ \\
\hline NIH-Toolbox Cognitive Tests (mean, SD) & & & \\
\hline Flanker test & $39.98(9.50)$ & $43.78(8.17)$ & -2.14 & 0.03 \\
\hline List sorting task & $49.34(10.66)$ & $53.18(8.32)$ & -2.01 & 0.05 \\
\hline Dimensional Change Card Sort test & $46.38(11.94)$ & $54.76(13.20)$ & -3.33 & $<0.01$ \\
\hline Pattern comparison task & $49.76(16.21)$ & $57.36(14.44)$ & -2.47 & 0.02 \\
\hline
\end{tabular}

This article is protected by copyright. All rights reserved 
Table 3. Aggregate EMA cognitive functioning variables

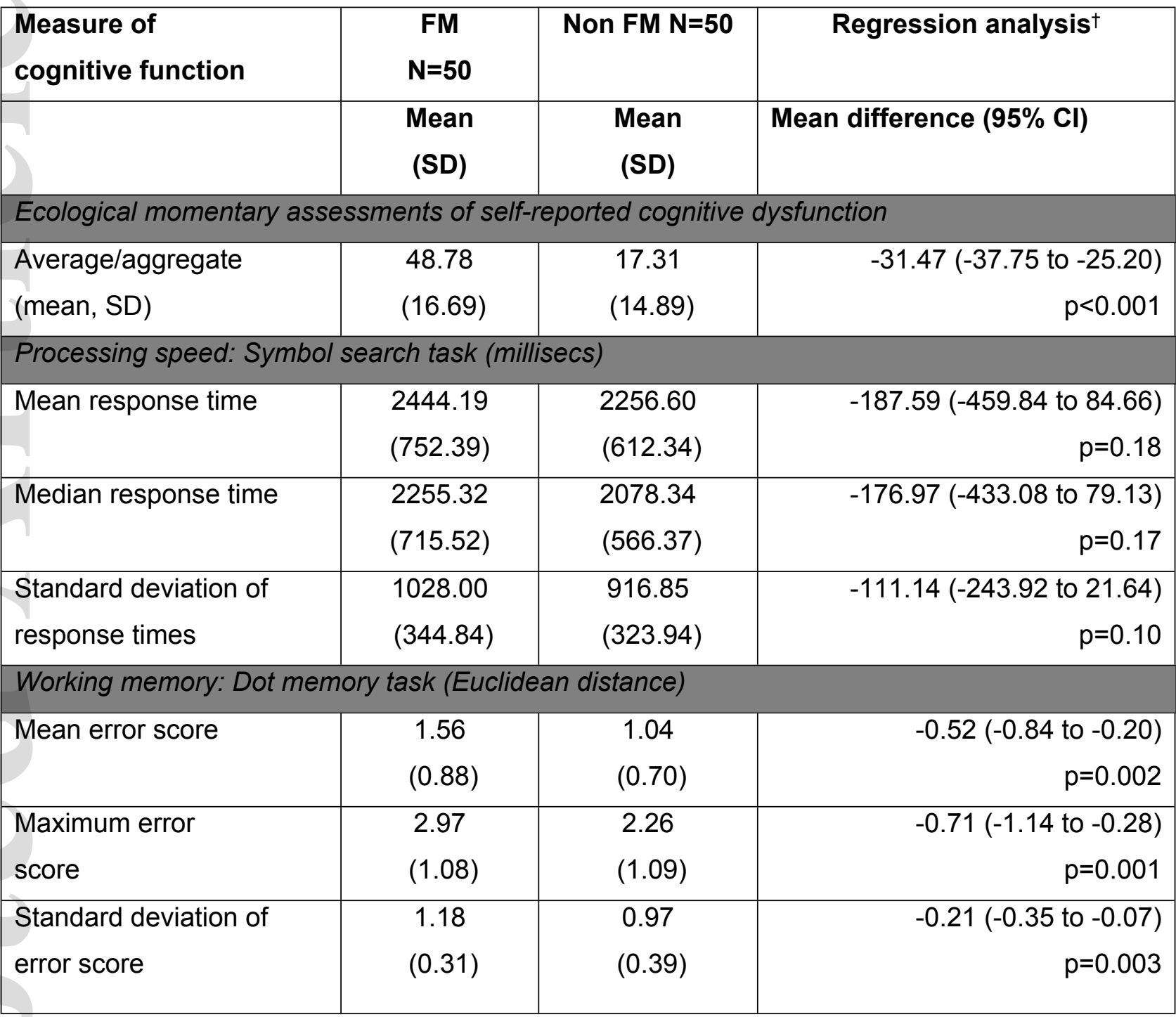

†Reference group: FM group

This article is protected by copyright. All rights reserved 
Table 4. The association between within-person variation in objective cognitive function and momentary self-reported cognitive function (criterion variable) adjusted for Group ${ }^{\dagger}$

\begin{tabular}{|l|r|r|r|r|r|}
\hline & \multicolumn{1}{l|}{$\begin{array}{l}\text { Effect } \\
\text { estimate }\end{array}$} & SE & $95 \%$ Cl & \multicolumn{1}{l|}{} \\
\hline Within-person variation in processing speed: symbol search task mean response time \\
\hline Intercept & 48.10 & 2.43 & $43.33,52.87$ & $<0.001$ \\
\hline Session number & 0.03 & 0.04 & $-0.05,0.12$ & 0.43 \\
\hline Person-centered mean response time & 0.006 & 0.001 & $0.004,0.007$ & $<0.001$ \\
\hline Group & -31.31 & 3.15 & $-37.48,-25.13$ & $<0.001$ \\
\hline Within-person variation in processing speed: symbol search task median response time \\
\hline Intercept & 48.08 & 2.44 & $43.30,52.86$ & $<0.001$ \\
\hline Session number & 0.04 & 0.04 & $-0.05,0.12$ & 0.42 \\
\hline Person-centered median response time & 0.006 & 0.001 & $0.004,0.008$ & $<0.001$ \\
\hline Group & -31.31 & 3.15 & $-37.49,-25.13$ & $<0.001$ \\
\hline
\end{tabular}

\begin{tabular}{|l|r|r|r|r|r|}
\hline \begin{tabular}{l} 
Within-person variation in processing speed: symbol search task standard deviation of \\
response times \\
\hline Intercept
\end{tabular}$\quad 49.13$ & 2.41 & $44.41,53.85$ & $<0.001$ \\
\hline Session number & -0.03 & 0.04 & $-0.11,0.05$ & 0.51 \\
\hline Person-centered SD of response times & 0.003 & 0.001 & $0.002,0.005$ & $<0.001$ \\
\hline Group & -31.32 & 3.15 & $-37.49,-25.14$ & $<0.001$ \\
\hline Within-person variation in working memory: dot memory task - mean error & \\
\hline Intercept & 49.50 & 2.41 & $44.77,54.22$ & $<0.001$ \\
\hline Session number & -0.04 & 0.04 & $-0.12,0.04$ & 0.29 \\
\hline Person-centered mean error & -0.10 & 0.41 & $-0.91,0.71$ & 0.80 \\
\hline Group & -31.45 & 3.15 & $-37.63,-25.28$ & $<0.001$ \\
\hline Within-person variation in working memory: dot memory task - maximum error & \\
\hline Intercept & 49.53 & 2.41 & $44.80,54.25$ & $<0.001$ \\
\hline Session number & -0.05 & 0.04 & $-0.12,0.03$ & 0.27 \\
\hline Person-centered maximum error & -0.16 & 0.23 & $-0.61,0.28$ & 0.47 \\
\hline Group & -31.46 & 3.15 & $-37.63,-25.28$ & $<0.001$ \\
\hline Within-person variation in working memory: dot memory task - standard deviation of errors \\
\hline
\end{tabular}

This article is protected by copyright. All rights reserved 


\begin{tabular}{|l|r|r|r|r|}
\hline Intercept & 49.53 & 2.41 & $44.80,54.26$ & $<0.001$ \\
\hline Session number & -0.05 & 0.04 & $-0.12,0.03$ & 0.27 \\
\hline Person-centered SD of error & -0.48 & 0.48 & $-1.41,0.45$ & 0.31 \\
\hline Group & -31.46 & 3.15 & $-37.63,-25.28$ & $<0.001$ \\
\hline
\end{tabular}

${ }^{\dagger}$ Reference group: FM

This article is protected by copyright. All rights reserved 